\title{
Cristóbal Suárez de Figueroa: un enemigo de América y de los indianos en la España del XVII
}

Héctor Brioso Santos

Universidad de Alcalá

Aunque la imagen de América en la literatura española del Siglo de Oro no ha sido todavía analizada con demasiado detenimiento por los hispanistas, hay que destacar que el personaje del indiano - el emigrante español en las Indias Occidentales-es condenado por un escritor en prosa de Valladolid, el doctor Cristóbal Suárez de Figueroa, en su obra de ficción El pasajero, de 1617. En ese relato, Suárez desaprueba la colonización y, sin defender abiertamente a los indígenas, ataca a los indianos por su codicia, ignorancia y doblez. En este estudio, la denuncia de ese autor es contrastada con otras visiones de sus contemporáneos, en general más matizadas.

Palabras Clave: América, indiano, denuesto, colonialismo, Siglo de Oro, Suárez de Figueroa, Lope de Vega.

Although the image of America in the Spanish literature of the Golden Age has not been analyzed very often by the hispanists, it is remarkable that the character of the indiano - the Spaniard that emigrated to the Indias - is condemned by a prose writer from Valladolid, Dr. Cristóbal Suárez de Figueroa, in his fictional work El pasajero, dated in 1617. In that narrative, Suárez strongly disapproves colonization and, without openly defending aborigines, attacks the indianos on the grounds of their greed, ignorance, and double-dealing. In this study, Suárez's denounce is compared to other contemporaries' more moderate views.

KEYWORDS: America, indiano, insult, colonialism, Golden Age, Suárez de Figueroa, Lope de Vega.

A pesar del indudable interés del asunto y del buen ejemplo dado por filólogos, antropólogos e historiadores de otros países de Europa y de los Estados Unidos, ${ }^{1}$ no es todavía demasiado frecuente encontrar estudios

1 Los mejores estudios desde el lado anglosajón siguen siendo los de Greenblatt, Stephen: Marvellous Possessions. The Wonder of the New World, The University of Chicago Press, Chicago, 1991; Grafton, Anthony: New Worlds, Ancient Texts. The Power of Tradition and the Shock of Discovery, Belknap Press, Cambridge, 1992; y Greene, Jack P.: The Intellectual Construction of America. Exceptionalism and Identity from 1492 to 1800, The University of North Carolina Press, Chapel Hill, 1993. Desde Hispanoamérica, un trabajo valioso, aunque poco recordado, es el de Henríquez Ureña, Pedro: "El Nuevo Mundo en la imaginación de Europa", en Cedomil Goic (coord.): Historia y crítica de la literatura hispanoamericana, Crítica, Barcelona, 1988, vol. I, págs. 49-53. 
acerca del impacto de las Indias en la literatura española del Siglo de Oro, aunque, en sentido inverso, los balances más o menos críticos o revisionistas del dominio del continente americano por su metrópoli y los repasos historiográficos de los informes — crónicas y relaciones - que las autoridades metropolitanas hicieron de sus posesiones son numerosos y conocidos. $^{2}$

Sobre el indiano literario en particular, muchos estudiosos han registrado correctamente las tendencias más habituales de la época a la instrumentalización del personaje o a su denigración en los textos. Se ha señalado, por ejemplo, el tono amargo y moral de Cervantes en el célebre comienzo de su novela ejemplar de El celoso extremeño, donde se narra magistralmente la peripecia de su protagonista, el pródigo y vicioso Felipo de Carrizales. ${ }^{3}$

No puede negarse que una porción importante de las menciones de América soslayan o maltratan a los colonos de entonces, los llamados indianos. Tampoco cabe ignorar el hecho de que el Nuevo Mundo tiene, en términos brutos, una reducida representación en la literatura española contemporánea escrita en la Península y que buena parte de esa representación americana consiste en la aparición de indianos en las páginas de la novela o en el escenario de las comedias de capa y espada. Acaso las dos tendencias están relacionadas entre sí y el indiano ejerce como representante de Ultramar en la cultura de la metrópoli, sobre todo a tenor de la relativa escasez de apariciones de indígenas o de alusiones a ellos en nuestra literatura clásica.

Precisamente, dadas las limitaciones de un artículo, me propongo ahora atar algunos cabos acerca de esta cuestión armado de un número corto de testimonios procedentes de una única fuente, que podrán ampliarse

2 Véase un panorama parcial en Block, David: "Quincentennial Publishing: An Ocean of Print”, Latin American Research Review, 29 (1994), págs. 101-128.

3 Cervantes Saavedra, Miguel de: Novelas ejemplares, Avalle-Arce, Juan B. (ed.), Madrid, Castalia, 1982, vol. II, págs. 175-176. Véase el comentario del editor en pág. 175, especialmente nn. 3 y 4, y las anotaciones más sucintas —al menos en cuanto al tema americano- de Jorge García López en su propia edición de esas novelas (Crítica, Barcelona, 2001, págs. 326 y 886), así como los estudios de Dunn, Peter N.: "Las Novelas ejemplares", Avalle-Arce, Juan Bautista, y Riley, Edward C. (eds.): Suma cervantina, Tamesis, Londres, 1973, págs. 81-118; y Molho, Maurice: "Aproximación al Celoso extremeño", Nueva Revista de Filología Hispánica, 38 (1990), págs. 743-792. He revisado el pasaje, con abundantes fuentes bibliográficas e históricas, en varios lugares: en el libro América en la prosa literaria española de los siglos XVI y XVII de 1999 (Diputación Provincial, Huelva, 1999, págs. 121122) y después en mi estudio cervantino de 2006, Cervantes y América (con la colaboración de José Montero Reguera), Fundación Carolina-Marcial Pons, Madrid, 2006, págs. 139-155 y 199-200. 
bastante más en otros sucesivos. En efecto, por poner un ejemplo muy extremo de las idiosincrasias de un sector de la intelectualidad española del XVII, el más enconado que conozco sin entrar en un dominio como el de las crónicas, en el que autores como el padre Las Casas o Fernández de Oviedo ofrecen párrafos memorables sobre la codicia de los colonos, soldados y clérigos españoles, recordaré que el lector de El pasajero de Cristóbal Suárez de Figueroa (1617) se encuentra en una de las páginas de esa amena miscelánea de viaje con una auténtica condena de los indianos y de la colonización.

Vayamos por partes. Los anatemas literarios contra el invento de la navegación en general y, siglos después, contra el periplo a Indias en particular no son infrecuentes desde la antigüedad latina, sino que aparecen señaladamente en obras de Petrarca, Luis de Camoens, fray Luis de León, Francisco de Quevedo o Luis de Góngora, entre muchos otros, como he estudiado en un artículo de hace años. Bastará un ejemplo poco conocido de esta condena extraído de la novela Vida de Marcos de Obregón de Vicente Espinel (donde, además, se recuerda un chiste antimarítimo del autor cordobés de Las soledades):

Confiado yo en que sabía nadar y los otros no, arrojéme al charco de los atunes, como dice don Luis de Góngora, donde me pudiera suceder lo que al escarabajo, si Dios no lo remediara, que para una bestia tan cruel y desleal como el mar no aprovecha saber nadar; que echarse un hombre en el mar es echarse un mosquito en la laguna Urbión. Los animales de la tierra están enseñados a tratar con un elemento fiel, amigable, suave y apacible, que dondequiera da acogida y sustenta al cansado; pero el mar ingrato, tragador de los bienes de la tierra, sepultura perpetua de lo que en él se esconde, que se sale a la tierra a ver si puede llevarse adentro lo que está en la orilla; hambriento animal de todo lo que puede alcanzar; asolador de ciudades, islas y montañas; envidioso enemigo de la quietud, verdugo de vivos y despreciador de muertos, y tan avariento, que estando lleno de agua y de peces mueren en él de sed y de hambre, ¿qué puede hacer sino destruir a quien dél se fiare? ${ }^{4}$

Y en una obra de veinte años después, las Empresas políticas de Diego de Saavedra Fajardo (1640), todavía leemos, en su empresa doceava, que "no hay arte mágica y diabólica que no se ejercitase en el descubrimiento del oro y de la plata", en clara alusión a las Indias Occidentales y a los viajes a ellas encaminados. ${ }^{5}$

4 Espinel,Vicente: Vida de Marcos de Obregón, Gili Gaya, Samuel (ed.), Espasa-Calpe, Madrid, 1969, II, págs. 202-203.

5 Saavedra Fajardo, Diego de: Empresas políticas, Díez de Revenga, Francisco J. (ed.), Planeta, Barcelona, 1988, pág. 93. 
Todo esto se había convertido en un tópico de dominio público desde, por lo menos, la aparición del Libro de los inventores del arte de marear guevariano. El mismo Suárez de Figueroa anota un discurso en el que el personaje del Doctor protesta también contra la navegación:

No deben los que navegan contarse con los vivos ni con los muertos; mas como gente que tiene su vida puesta en balanza. Sólo el esperar les conserva un cierto rastro y sombra de la vida, siendo él sólo en tanto peligro su aliento y su vivir. ¿Hay trance tan espantoso como es estar los que navegan no más lejos de la muerte de cuanto tiene de grueso la tabla del navío, casi como desesperados de todo remedio? Grande audacia fue (dice Plinio) querer probar el mar; ni fue sin injuria de los hombres la temeridad del que tal arte inventó. ¿No le bastaba la tierra para sepultura, sin querer también eligir la mar, o que careciesen muchos de la misma, muriendo en ella... ${ }^{6}$

Pero el extremismo de Suárez lo hace transitar desde el hermoso cauce horaciano consabido hacia la ruta del más acendrado antagonismo contra Ultramar, expresado a través del puro insulto. Ese escritor destila también en esta parrafada un odio mal contenido en el resto de la obra.

El abogado vallisoletano Cristóbal Suárez de Figueroa era hombre descontentadizo y envidioso de los que tenían más éxito que él, ya fuera éste literario o económico, por lo que sus libros aparecen plagados de esta suerte de anatemas y de las malquerencias del entonces apodado Fisgarroa, personajillo que - al decir de lenguas no menos malas que la suya - fisgaba y roía la fama y el prestigio de otros. En este punto saca a colación Suárez reparos grandes y pequeños contra la colonización hispana del Nuevo Mundo y, lo que es más importante y menos frecuente, contra la propia América como fuente de problemas de alcance nacional. Va más allá en ese punto que los arbitristas que habitualmente proponían entonces una política exterior basada en las reformas en la política dentro de la Península y en la contención internacional. E incluso supera a un Miguel Caxa de Leruela, que anotaba que América era un señuelo engañoso para la economía española:

Este daño tuvo principio conocidamente del descubrimiento de las Indias, porque al cebo de aquellos tesoros han pasado a ellos millones de naturales, y los extranjeros pusieron todo su estudio en ministrar, a los que quedan, comodidades y delicias, y dis-

6 Guevara, Antonio de: Libro de los inventores del arte de marear, López Bascuñana, María Isabel (ed.), PPU, Madrid, 1988, pág. 338. En lo que sigue, insertaré en el texto, entre paréntesis, las referencias sucesivas a las dos obras literarias citadas reiteradamente. Pese a la contundencia de las palabras citadas arriba, otro personaje hará a continuación una defensa del arte de navegar (pág. 340). 
traerlos de la costumbre antigua, y del trabajo, y ocupación, pasando de las cosas útiles a curiosidades impertinentes, inventando tantas maneras de sacaliñas (...) (p. 60).

Frente a este ponderado economicismo, nuestro autor hace una declaración como la siguiente, que transcribo por extenso en razón de su interés:

Las Indias, para mí, no sé qué se tienen de malo, que hasta su nombre aborrezco. Todo cuanto viene de allá es muy diferente, y aun opuesto, iba a decir, de lo que en España poseemos y gozamos. Pues los hombres (queden siempre reservados los buenos) iqué redundantes, qué abundosos de palabras, qué estrechos de ánimo, qué inciertos de crédito y fe; cuán rendidos al interés, al ahorro! ¡Qué mal se avienen con los de acá, observando diversas acciones, profesando diferentes costumbres; siempre sospechosos, siempre retirados y montaraces! ¡Pues la presunción es como quiera! Todos, sino ellos, ignoran, todos yerran, todos son inexpertos; fundando la verdadera sabiduría y la más fina agudeza sólo en estar siempre en la malicia, en el engaño y doblez. No he visto hacienda adquirida en aquellas partes lograda bien en las nuestras (...) (pág. 337).

Así pues, confiesa Suárez primero su odio incondicional hacia el Nuevo Mundo. Incluso les reprocha ser unas tierras novedosas —otros autores reproducirán este mismo reproche injusto fundado en la reticencia de su cultura a la novedad-, un lugar enteramente nuevo.

Semejante idea no indica sólo un prejuicio; constituye, además, la simple formulación de un importante hecho intelectual y epistemológico: la radical novedad de América, sus cosas y sus hombres sorprende desfavorablemente a muchos, que recelan ante tanta novedad y sugieren la peligrosidad económica, social, religiosa y moral de una empresa claramente dificultada por la terrible profundidad - dispuesta por el Creador para sustraerlos a la codicia de los hombres - a la que están sepultados el oro y la plata en el Nuevo Mundo, el peligroso océano, los desastres naturales, la codicia criminal de los españoles y la piratería internacional.

Mas quien denuesta el lugar, denuesta a sus habitantes, al emigrante que a él aporta y al que lo visita circunstancialmente. Suárez, como muchos escritores, la emprende contra el indiano, cabeza de turco de mil críticas intelectuales a la conquista en diversos géneros de la literatura, desde el

7 El primer comentario que conozco de estas líneas es el de Américo Castro en su De la edad conflictiva: crisis de la cultura española en el siglo XVII, Taurus, Madrid, 1976, pág. 216n., donde asegura que "Suárez de Figueroa odiaba a las Indias y a los enriquecidos en ellas". Véase también mi estudio ya citado de 1999, donde comentaba brevemente parte del pasaje (págs. 110-111), aunque en bastantes más lugares del libro aludía a Suárez. 
entremés hasta la novela y la poesía. ${ }^{8}$ Como hemos visto, en efecto, del indiano destaca Suárez, con una cristiana salvedad para los mejores de entre ellos —según hemos visto: "queden siempre reservados los buenos"-, la redundancia y la verbosidad. En general, el indiano es habitualmente, tanto en este tipo de alegatos como en las más ligeras comedias, un exagerado e insoportable charlatán, un mentiroso y un cobarde, aunque, por lo común, estas acusaciones se le hagan en tono de solfa, con una gracia que no exhibe Suárez de Figueroa en su pasaje.

El interesante Diccionario de la comedia define al indiano teatral como "un hombre ya mayor, rico pero grosero y avariento, que a veces aparece como antagonista del galán en comedias de capa y espada ambientadas en España". ${ }^{9}$ Porque, el indiano es, amén de codicioso, supremamente tacaño o, según reza la voz acuñada casi en exclusiva para él, guardoso. De ahí que Fisgarroa les reproche: "i...cuán rendidos al interés, al ahorro!". Casi parecen confirmar estas palabras una conjetura de Américo Castro acerca de que sobre los indianos podía pesar una sospecha de judaísmo. ${ }^{10}$ Es posible que ésta obrase en la mentalidad de Suárez, aunque no tenemos pruebas de que así fuera, ni en su caso ni en el de muchos otros escritores adheridos a esta campaña anti-indiano.

Castro, en efecto, señalaba, en su libro polémico Cervantes y los casticismos españoles, que “(...) La riqueza de los 'indianos' no daba honores, y el oro de las Indias no remediaba la pobreza de España". ${ }^{11} \mathrm{Y}$ anotaba además estas consideraciones:

La significación de las Indias para los españoles que permanecían en la Península está bien clara: enriquecerse en el Nuevo Mundo ponía en peligro la limpieza del linaje, convertía al indiano en un posible judío, interesado en acumular una fortuna individual y secular (no como aureola de su rango nobiliario o para fines religiosos). ${ }^{12}$

8 Sobre los emigrantes reales, pueden verse el estudio muy detallado de González Sánchez, Carlos A.: Dineros de ventura: la varia fortuna de la emigración a Indias (siglos XVI-XVII), Universidad de Sevilla, Sevilla, 1995; y el muy evocador de Martínez, José Luis: Pasajeros a Indias, Alianza, Madrid, 1980.

9 Casa, Frank P.; Vega García-Luengos, Germán, et al. (dirs.): Diccionario de la comedia del Siglo de Oro, Castalia, Madrid, 2002, pág. 8.

10 Véase hoy, para la vertiente histórica de este problema racial-castizo, el excelente libro de Domínguez Ortiz, Antonio: Los judeoconversos en España y América, Istmo, Madrid, 1988.

11 Castro, Américo: Cervantes y los casticismos españoles, Alianza, Madrid, 1974, pág. 233.

12 Ibídem. 
La codicia sí era atributo frecuente del colono real ${ }^{13} \mathrm{y}$ del indiano literario, según lo formulase ya Alonso de Ercilla en su poema La Araucana, en versos lapidarios:

Codicia fue ocasión de tanta guerra

y perdición total de aquesta tierra. ${ }^{14}$

Y como ha estudiado en su libro Marcos Augusto Morínigo. ${ }^{15}$

La consideración siguiente en la terrible enumeración de pecados que entona el Doctor es la relativa al difícil retorno del indiano a su patria. El lector recordará los recelos y el extraño ambiente que atemorizan al celoso extremeño cervantino, bien pertrechado de oro americano y medroso de cualquier injerencia del exterior en su nueva vida de casado en Sevilla. Con todo, el desarrollo de la novela ejemplar resulta infinitamente más rico que la alusión de Suárez, pues Cervantes rechaza las obviedades del indiano avaro y desconfiado, oculto en su rincón, o las del personaje parlanchín, fabulador y mentiroso, para atribuirle un tópico mucho más antiguo y fecundo: el del viejo celoso casado con la niña, ahora en versión seria y en tono de más hondo análisis psicológico.

En cambio, el amargado Suárez de Figueroa, sin la sutileza, la habilidad y la imaginación cervantinas, se contenta con entonar su sarta de improperios ya citada, que incluye la incompatibilidad con los peninsulares (“iQué mal se avienen con los de acá...!”); su alejamiento del modo de ser de los verdaderos españoles ("observando diversas acciones, profesando diferentes costumbres"); y su carácter arisco, retraído e insociable ("siempre sospechosos, siempre retirados y montaraces!").

Ahora bien, como el tópico es, en realidad, una madeja de lugares comunes muy mal avenidos entre sí, comprobamos que el indiano puede ser retirado y montaraz, presuntuoso y hablador a un mismo tiempo: "iPues la presunción es como quiera!"; a la par que resulta tan seguro de sí, que

13 Como escribía Las Casas en su Brevísima relación de la destrucción de las Indias: "La causa porque han muerto y destruido tantas y tales y tan infinito número de ánimas los cristianos, ha sido solamente por tener por fin último el oro y henchirse de riquezas en muy breves días, y subir a estados muy altos y sin proporción de sus personas, conviene a saber, por la insaciable cudicia y ambición que han tenido... [Saint-Lu, André (ed.), Cátedra, Madrid, 1993, págs. 78-79]. pág. 175.

14 Morínigo, Marcos A., y Lerner, Isaías, (eds.), Castalia, Madrid, 1979, estr. 3, canto III,

15 América en el teatro de Lope de Vega, Instituto de Filología, Buenos Aires, 1946, en el capítulo titulado expresivamente "Indiano: codicioso" (págs. 156-157). 
habla y porfía en demasía con otras personas —el porfiado, el obsesivo es otro tipo satírico menor de la época-: "Todos, sino ellos, ignoran, todos yerran, todos son inexpertos; fundando la verdadera sabiduría y la más fina agudeza sólo en estar siempre en la malicia, en el engaño y doblez".

Aquí se ha alcanzado uno de los límites críticos del personaje. Éste, si bien había sido acusado de astucia maliciosa por Lope de Vega en $L a$ Dorotea,${ }^{16}$ no es generalmente tan engañoso en la literatura como lo pinta Suárez, que extrema la nota en su catálogo de defectos. Más bien el indiano solía ser acusado de hablador vano y de chapetón, o sea, de inexperto y fácil de embaucar, como en la misma Dorotea es llamado don Bela - "chapetón de la Corte (que así llaman ellos a los modernos)" (pág. 178)—. Aunque también se anota la idea contraria en esa obra: "Siempre oí decir que los indianos hablan mucho, si bien todo es bueno, porque aquel clima produce raros y sutiles ingenios" (págs. 184-185).

Lo corriente, en el medio literario contemporáneo de nuestro autor, era, en realidad, un personaje dúctil y acomodado a las necesidades de cada argumento. Precisamente el don Bela indiano de la acción en prosa del Fénix resulta un carácter equilibrado y es descrito en esa obra desde varios ángulos. Obsérvese que, para empezar, en el tratamiento magistralmente complejo de su viejo episodio de juventud, Lope dispone nada menos que dos indianos en la vida de Dorotea: un marido presuntamente fallecido en Lima - Ricardo (pág. 135) - y el pretendiente enamorado y rico que es don Bela, rival del protagonista don Fernando, trasunto del propio Lope. La caracterización de Bela, es múltiple: por medio de una descripción favorable e interesada de Gerarda, una amiga de la madre de la dama, directamente por la aparición del mismo Bela, e indirectamente, por vía de un Arancel con que ha de andar un caballero en la Corte enderezado a prevenir a los recién llegados contra alcahuetas y pedigüeños. Frente a la ingenuidad que sugiere el último texto, don Bela es en realidad un indiano precavido y astuto que conseguirá finalmente a la sufrida Dorotea. Y no en vano, en esa pieza lopiana, la celestina Gerarda intenta incitar a Teodora para que persuada a Dorotea a que se entregue al indiano, pues éste es hombre rico, maduro, discreto y liberal, esto es, generoso con sus caudales. Con ese fin, traza Gerarda ante su amiga un retrato físico del personaje:

16 El personaje americano es descrito como "muy entendido, despejado y gracioso" desde el comienzo de esa obra [Vega Carpio, Félix Lope de: La Dorotea, Morby, Edwin S. (ed.), Castalia, Madrid, 1987, pág. 83]. 
Es hombre de hasta treinta y siete años poco más o menos, que unas pocas de canas que tiene son de los trabajos de la mar, que luego se le quitarán con los aires de la corte; y yo vi el otro día un rótulo en una calle que decía: "Aquí se vende el agua para las canas". Tiene linda presencia, alegre de ojos, dientes blancos, que lucen con el bigote negro como sarta de perlas en terciopelo liso; muy entendido, despejado y gracioso; y, finalmente, hombre de disculpa, y no mocitos cansados, que se llevan la flor de la harina y dejan una mujer en el puro salvado, que ya entendéis para lo que será buena (págs. 82-83).

Aunque Dorotea acabará por rendirse a los encantos del maduro personaje y abandonará al infeliz don Fernando —un Lope joven, poeta y pobre- en un principio se resiste a la seducción lanzando una andanada contra los argumentos de su madre: “¡Notable batería hizo en el muro de tu entendimiento la fisionomía liberal del rico indiano! ¡Así suelen ser ellos, como te le pintó la Circe!", en alusión clara a la celestina Gerarda, que se entromete en sus amores (pág. 86).

En realidad, la más dura crítica de muchos españoles a los indianos estribaba, como tantas cosas, en un móvil de la más rancia economía, ${ }^{17}$ justamente subrayada por Lope en el pasaje citado y en otros, como el del sueño de Fernando, en el que, desde una nave, "un hombre solo - trasunto onírico de don Bela-, que desde el corredor de popa arrojaba a una barca barras de plata y tejos de oro", riquezas que una Dorotea imaginaria recoge "con las dos manos" (pág. 92). Esto es, exactamente el cuadro habitual de la relación entre las depauperadas mujeres cortesanas y sus amantes ricos provenientes de Indias.

En el mismo orden de cosas, sobre Bela sabremos que es "liberalísimo". ${ }^{18}$ También se anota que es "muy discreto" y que "ha visto mucho mundo" (pág. 195). Y después leemos otro encendido elogio: “¡Mira que sabiduría con aquel talle! Entendimiento tiene que podría ser feo" (pág. 198), porque el indiano sabio no cesa en ese pasaje de perorar sobre Teócrito, Virgilio, el romancero y Orfeo (págs. 198-199).

Volviendo a nuestro autor, uno de los últimos puntos aducidos por Suárez consiste en la idea de que la hacienda americana no fructifica ni enriquece a sus nuevos propietarios peninsulares a causa de haber sido

17 Todo esto ha sido estudiado, en su vertiente histórica, en la que no entraré aquí, por Hamilton, Earl J.: El tesoro americano y la revolución de los precios en España, 1501-1650, Ariel, Barcelona, 1975.

18 En la pág. 187 y también 188 y 190, con cierta insistencia. En la pág. 190 leemos que es nada menos que un "liberalísimo príncipe". 
obtenida de forma pecaminosa por los colonos en las mismas Indias: "No he visto hacienda adquirida en aquellas partes lograda bien en las nuestras". Así, con una frase lapidaria, Suárez de Figueroa sentencia al indiano de la literatura y de la realidad. El tópico podía ser más complicado aún en esos años, pues solía acusarse a los emigrantes de dejar sus conciencias en España antes de partir a Ultramar, en Sevilla, como escribe Mateo Alemán en su Guzmán de Alfarache:

Donde hay muchas escuelas de niños, y maestros que guardan conciencias —aunque, como digo, ninguna ciudad, villa, ni lugar se escapa en todo el mundo- es en Sevilla, de los que se embarcan para pasar la mar, que los más dellos, como si fuera de tanto peso y balume que se hubiera de hundir el navío con ellas, así las dejan en sus casas o a sus huéspedes, que las guarden hasta la vuelta. ${ }^{19}$

Sólo después de explayarse a gusto contra los colonos emigrantes, piensa Suárez en recapitular enfáticamente con una postrera andanada de denuestos:

¡Qué deslucidos casi todos, qué míseros, qué faltos de amistad, qué sobrados de odio, qué inútiles, qué despegados, qué malquistos! ¡Notables sabandijas crían los límites antárticos y occidentales! (pág. 337).

Mientras que añade la nota personal del resentido, no poco retórica en este caso:

Desde que nací aguardo venga de allá algún varón no menos rico que espléndido en quien tenga albergue la virtud, amparo la ciencia, socorro la necesidad (pág. 337).

Y, a modo de recapitulación, recuerda un tópico reciente de Lope de Vega ${ }^{20}$ ahora extendido desde el palenque de las glorias épico-literarias a todos los campos:

¿Es posible no haya producido en más de un siglo aquella tierra algún sujeto heroico en armas, insigne en letras, o singular por cualquier camino? ${ }^{21}$

19 Alemán, Mateo: Guzmán de Alfarache, Micó, José M. (ed.), Cátedra, Madrid, 1987, pág. 387. Véase mi estudio "El tópico barroco de las 'anchas conciencias' de indianos y mercaderes", Revista de Indias, LXV-235 (2005), págs. 775-786.

20 Véase su Dragontea, publicada en 1598, en Obras selectas, Sáinz de Robles, Federico C. (ed.), Aguilar, Madrid, 1964 [1947], II, págs. 365-366.

21 Ibídem. 
Evidentemente, nuestro autor no piensa en este instante ni en los Varones ilustres, ni en los héroes ercillanos o en la misma Araucana, ni en la famosa epístola de Lope de Vega a la Amarilis Indiana, ni en los ingenios americanos del Canto de Caliope de Cervantes. Tampoco repara en un título de un capítulo de Juan de Cárdenas, "Qual sea la causa de ser todos los Españoles nacidos en Indias por la mayor parte de ingenio bivo, tracendido y delicado". 22

La última frase del pasaje de Suárez de Figueroa retorna al lugar común del interés, o sea, la codicia del oro y la plata que sugirió a Castro su razonamiento y que campa por doquier a lo ancho de la literatura española barroca más crítica contra la colonización de las Indias: "Mas ¿qué puede haber en parte donde tanto triunfan los vicios, donde tanto campea el interés?". ${ }^{23}$

La arenga de Fisgarroa ha concluido. Frente a ella, se alinean algunos - pocos - textos de otros escritores que defienden a los indianos, como la Refutación de Las Casas de Bernardo Vargas Machuca, y decenas de autores que se sirven del carácter del indiano para enriquecer sus respectivos catálogos de criaturas narrativas y teatrales, bondadosas o mendaces, habladoras o reservadas, graciosas o siniestras en función de las variadas necesidades de las tramas teatrales o narrativas en las que participan. ${ }^{24}$ Porque a pesar de los grandes esfuerzos propagandísticos, tanto de Suárez como de sus antagonistas, ni toda la literatura contemporánea aparece enconada contra el colono y la colonización, ni toda ella refleja una creencia firme en la incorporación benéfica y pacífica de Ultramar al Imperio español.

En suma, sería de desear que los estudiosos y los historiadores del futuro se acercasen al problema del impacto de lo americano en la literatura del XVII y ofrecieran soluciones equilibradas y ecuánimes que tuvieran en cuenta que el patriotismo a destiempo y las leyendas antiespañolas no hacen ninguna justicia a la imagen literaria de América en la España barroca, unas veces teñida de un retoricismo estéril y otras de un indigenismo en

22 Primera parte de los problemas y secretos maravillosos de las Indias, Imprenta del Museo Nacional de Arqueología, Historia y Etnología, México, 1913, Libro III, cap. II; págs. 159-163.

23 Añádase a sus contribuciones al tema ya citadas la nota "Sobre lo precario de las relaciones entre España y las Indias”, en Cervantes y los casticismos..., págs. 228-244.

24 Tal y como intenté demostrar en mi artículo de 1998: "La figura grotesca del indiano teatral en el Siglo de Oro español", en Reverte Bernal, Concepción, y de los Reyes Peña, Mercedes (eds.): II Congreso Iberoamericano de Teatro "América y el teatro Español del Siglo de Oro", Universidad de Cádiz, Cádiz, 1998, págs. 423-434. 
ciernes que sorprendería a muchos, o - finalmente - de un anticolonialismo tan extemporáneo y tan poco ecuánime como es el de Suárez de Figueroa o Fisgarroa.

Y, aunque no sea éste el objeto de estudio de estas notas, más interesadas en la imagen del colono, no podemos por menos de destacar el testimonio verdaderamente lascasiano de nuestro autor:

Mas ¿qué puede haber en parte donde tanto triunfan los vicios, donde tanto campea el interés? Todo es destruir, todo es aniquilar las vidas y haciendas de los que tienen entre manos. Tiranos crueles, no blandos mayordomos de los bienes y frutos de aquellos simples, de aquellos inocentes, que sumergidos entre las ondas del perpetuo trabajo, despiden las miserables vidas que les quedan, librándose con una de casi infinitas muertes; que por instantes les resulta del incesable sudor, de la insufrible fatiga. Siendo esto así, y que, según se afirma generalmente, los buenos se estragan en pisando aquellos confines, ¿de qué sirve para buscar su daño entregarse a los tremendos peligros y a las innumerables molestias de tan larga navegación? (pág. 338).

Recibido el 25 de enero de 2007 Aceptado el 1 de abril de 2007 